\title{
Walk in/walk as my shoes: puppetry and prosocial empathy in healthcare
}

\section{Cariad Astles, Royal Central School of Speech and Drama/University of Exeter}

\author{
Abstract \\ This article explores the connections between puppetry performance practice and the \\ activation of empathy, considering the synergies between puppetry and medical practice \\ where empathy is a key factor in healing. I draw on a consideration of the place of puppetry \\ within ritual transitional and healing practices to develop an examination of contemporary \\ modes of performance which require deep listening, response and attention. I examine the \\ connections between neuroscience and puppetry which suggest that attitude-taking engenders \\ empathy, and compare this to my ewn-puppetry training practice to suggest that training for \\ and engaging in puppetry practice can encourage and stimulate empathy. This in turn has \\ significance for practitioners of puppetry working in healthcare contexts, and for medical \\ practitioners who undertake some form of puppetry, either within their training or as \\ continuing professional development. Although the different forms of empathy are connected \\ in practice, the article focuses especially on affective (emotional), cognitive and social \\ empathy.
}

Keywords: puppetry, ritual, healing, empathy, care, healthcare, performance, transition

\section{Introduction}

This article analyses the specific ways in which puppetry practice can activate empathy. Additionally, I explore the deep resonances between empathy and puppetry through a consideration of both traditional and contemporary modes of puppetry performance, training and embodiment. The discussion of traditional modes focuses primarily on the ritual and healing aspects of puppetry; when discussing contemporary modes I discuss overarching principles of puppetry animation and analyse direct animation/table-top and multi-operated puppets more closely. I consider the modes and practices of puppetry which may be able to enable and enact empathetic processes and consider the specificity of the puppet in relation to its use within healthcare. While puppets are quite often used in medical situations, their function as healing objects in the contemporary world has been little studied. A number of puppeteers, psychologists and neuroscientists (as discussed below) have shown interest in the ways in which puppetry enables emotional response and identification, but there have been 
no overarching studies in the world to date of puppetry in healthcare and no academic studies of puppetry and empathy. This article is therefore significant in articulating and analysing the clear links between contemporary puppetry practice and empathy, and developing a clear case for its potential within healthcare. The article draws on my own practice as puppetry researcher, trainer and practitioner within healthcare contexts over ten years, my observations of others' work and practice, and my analyses of this work. While the article does not necessarily argue for the blanket use of puppetry in healthcare to enable better caring, it marks it clearly as a powerful mode of opening up debate about how healthcare practitioners work with vulnerable bodies, and an exploration of how people can be trained in caring practices and approaches; it also makes the case for deeper understanding of how this form of theatre, as well as its uses in entertainment, education and storytelling, can contribute to stronger and more positive ways of relating. Ultimately, within healthcare settings, there is a clear case for puppetry being used far more widely to promote healing.

Empathy has been a subject of study for several decades, primarily by psychologists, as a means of considering how we experience understanding of and connection with each other, and how empathy works within the brain to activate care for others. In more recent years, neuroscientists such as Christian Keysers and Valeria Gazzola of the Netherlands Institute for Neuroscience, and Michelle Trieu at the Kaiser Oakland Medical Centre in California, have become interested in how the brain can both be stimulated artificially to activate empathy and in turn how it is directly triggered through specific observations, actions or connections in daily life. I show in this article how the attitudes and actions of puppeteers towards their puppets, and the experiences of audiences watching puppetry, are similar to the experiences of participants experiencing empathy when observing others, within research experiments. This suggests a resonance between puppetry and empathy. In turn, therefore, puppetry may be a clinically useful practice where the development of empathy is considered to be beneficial for healthcare practitioners.

\section{Anecdote 1}

I first began working as a puppeteer in the late 1980s, with a Chilean puppet theatre company in London: Teatro Travesura. I later worked with the Little Angel Theatre in London and several other puppet theatre companies. Over these years, I began teaching and training in puppet theatre. I remember that I easily formed a strong bond with the puppets that I had been working with. I would take them home and practice; I did not treat them as dolls, feeding them, putting them to bed, etc, but I felt a deep connection. I cared about them and made sure 
that they were safe (stored appropriately) and in good condition. This was not a technical response to the needs of my tools; it was an affective engagement and responsibility. With the hindsight of this research, this could be considered a form of empathy. I did not think about it too much, but just put it down to the fact that I enjoyed what I did. I also found that when performing with the puppets, I cared very much about them in performance; how they stood, how they moved, how they reacted to other performers and puppets. I felt uncomfortable if their bodies were left in what looked like uncomfortable positions, or if they were not treated with respect. If their bodies came out of alignment in performance, it felt wrong and I hurried to correct it.

When I later began teaching puppetry at the University of Plymouth, I recall that a student who had engaged deeply with the practice of puppetry asked me: 'How do I do it better?' These were early days for me as a scholar-practitioner and I wanted to convey something to her beyond the request to practice more, to gain the technical mastery necessary to perform the puppet well; I wanted to convey to her the feeling of 'affective responsibility': responsibility with caring (Caswell and Cifor 2016: 24). I suggested that she do it with more love, and then felt foolish having said something so very un-academic. Years later, I return to that statement and suggest that in order to 'do it well', puppeteers need to engage in 'radical empathy' (which I will return to later in this article).

\section{Anecdote 2}

When my younger son was a small child, he spent several years in and out of Great Ormond Street Hospital for Children in London for treatment due to a serious accident and subsequent operation which went wrong. At this time he was fed via a tube into his stomach. In the playroom of the hospital there was a puppet with a similar gastrostomy which he became fascinated with: he grasped this puppet, cared for it and carried it around with him, rejecting all others, and took it into the operations with him. The experience of seeing this was very powerful for me. I saw that he perceived in the puppet something which is like me, but not me: a companion.

Both of these anecdotes testify to my perception of the power that puppetry has to awaken a powerful affective response, which will bring us later in this article to the discussion about the relationship between puppetry and empathy.

\section{Definitions and considerations of empathy}


Empathy is understood as the ability to understand, and, to some extent, identify with, the position, emotion and situation of others in such a way that it is felt or perceived through connection with the other. Within neuroscience it was defined by Paul MacLean in 1967 as 'the capacity to identify one's own feelings and needs with those of another person' (McLean 1967, cited in Marsh 2018: 110). It was originally believed that the areas of the brain connected with empathy were primarily within the prefrontal cortex of the brain, as this area of the brain was involved in emotional response and coordination; but Marsh notes that empathy reflects: 'multiple dissociable processes, many of which rely on ancient, subcortical structures that function similarly...' (Marsh 2018: 110). It is believed by psychologists and neuroscientists (Decety and Ickes 2009, Malikiosi-Loizos 2003, Marsh 2018, Segal 2018), that there are multiple types of empathy: cognitive (whereby we are able, through perspective-taking, to understand the positions and feelings of others); emotional or affective (whereby we perceive and can identify with the emotional state of others); social (whereby the value of empathy is seen as a collective position, benefiting all); and compassionate (taking actions to assist others); transactional and relational (a constant relational flow of emotion between parties); and even motor or somatic empathy (a response to physical pain). I mention these different types so that the ways in which puppetry is related to empathy can be clearly explored later.

The concept of empathy was first discussed within late nineteenth-century German aesthetics, as Einfühlung, which can be translated as 'feeling into'; and became part of twentieth-century discourse amongst European and North American psychologists generally. Empathy covers various social transactional and communicative modes and emotional and cognitive responses, which are socially modified; in other words, the ways in which we respond positively to others and identify with them, is also affected by our cultural and social conditioning, at least to some extent. Studies into empathy suggest that it may have social benefits: it can enable social and relational attunement; wider sharing; more compassionate responses to individual and social situations. It can additionally bring about a greater sense of purpose, wellbeing and value (Eisenberg and Strayer 1987; Malikiosi-Loizos 2003).

Some scholars have argued against empathy as an unquestionably positive attribute. Paul Bloom (2016) suggests that empathy is not particularly useful since feelings do not necessarily translate into actions. Bloom notes additionally that empathy could in fact give rise to actions which are unhelpful within the wider picture of human benefit. He gives the example of the 'identified victim', whereby people are drawn to assist a victim with a face and name, rather than responding to a clear need by a group of victims with whom one has no 
particular connection. Bloom also raises the question of potentially dangerous anger that could be aroused by the identification (through cognitive and affective empathy) with certain people or groups of people, suggesting that violent or excessively punitive action could result from over-empathising (Bloom 2016). Jesse Prinz (2011) had earlier argued that empathy is not necessary for moral behaviour. He suggests that empathy could in fact lead to lack of action, through the experience of being paralysed by feeling; he suggests that society is only changed by moral outrage, which empathy (in his opinion) does not provoke. He further proposes that as empathy is often associated with a person-to-person encounter, that it is not possible to feel empathy for a group. Both Bloom (2016) and Prinz (2011) suggest that empathy can cause unequal and discriminatory practice, since humans will tend to empathise with people from social groups similar to their own.

The arguments expressed above depend on certain assumptions: firstly, that empathy can only be felt as an encounter between two people; and secondly, that feeling does not necessarily translate into action. Empathy, however, does not necessarily disable the capacity for societal change; to empathise with someone does not mean that outrage at injustice is not felt. Furthermore, if human feeling can be experienced collectively, as communitas, then empathy for a collective experience can also be felt. In fact, to feel emotional empathy for one person may in turn give rise to greater sensitivity towards a group experiencing similar conditions. The puppet, as it is not identified with any single human person, can speak beyond the individual; as 'the common person', provoking empathy towards all in its situation.

This article does not intend to discuss, however, whether empathy can effect social and political change, but instead to consider how training in and practice of puppetry may activate social empathy in contexts of healthcare, leading to benefits for both patients and caregivers. My argument is based upon the idea that, despite contiguous and important social factors which may limit the extent of our empathetic response, engaging in acts of care through the body (as is the case within puppetry practice), does engender social empathy.

Keith Tudor (2011) discusses the social nature of empathy, whereby people respond to community and social needs through considering that empathy enables positive action. I suggest that there is a synergy between puppetry (in performance, training and healthcare) and cognitive, affective and social empathy which may lead to compassionate action. The anthropologist Joan Koss-Chioino (2006) considers radical empathy to be a choice to engage in empathy as a political and social stance which thereby translates into action. She defines it as a process of 'thinking and feeling into the minds of others' (Koss-Chioino 2006: 26, 
emphasis added). I suggest that this process of 'thinking and feeling into ...' is central to puppetry. Further, Caswell and Cifor consider that 'empathy is an affective demand of care' (Caswell and Cifor 2016: 30). Empathy, therefore, can engage us in care and social responsibility: social empathy. This has relevance for puppetry when considering its place within health and wellbeing. If puppetry stimulates social empathy, then wellbeing may be heightened overall.

Over the last ten years, neuroscientists have begun to study empathy more deeply. Keysers and Gazzola, of the Social Brain Lab in the Netherlands, conducted a series of experiments on people to explore the effects of observing another person's difficulty or pain (Armstrong 2017). Through the use of $\mathrm{fMRI}^{1}$ and $\mathrm{TMS}^{2}$ they were able to note that people observing another person engaged in a difficult activity unconsciously activated the same neural pathways as those undertaking the difficult activity themselves. This means that through 'motor mirror' activity, people are able to enter into 'vicarious states' of empathetic participation. This concept of a 'vicarious state' has great relevance for how we experience puppetry.

\section{Empathy and puppetry}

Figure 1. A Message from the Sea. Puppeteer animating table-top puppet. 30.05.19. Artwork by Paige Leaf-Wright. Image courtesy of the Royal Central School of Speech and Drama.

Puppetry practice is, by its nature, not only thinking and feeling into the minds of others, but also moving, performing and reacting into the body of an-other, or of others. In other words, when people are engaged in puppetry practice, they are already practising cognitive empathy by attempting to understand how people, beings and other consciousnesses may move, think, act and react. If we consider the example given above by neuroscientists Keysers and Gazzola, by sharing in the actions taken by the puppet, they will be activating empathetic response to the puppet through the neural pathways engaged in doing so. Puppetry, therefore, is already directly an act of cognitive empathy. By performing with puppets, responding to the needs of the puppet, they may also be triggering affective empathy, as they attempt to understand how a character, figure, or indeed, material might feel. If the empathetic responses achieved through their connection with audiences or participants lead to compassionate actions, within the performance or later, social empathy has also been achieved. This is something that I have observed through play with and care of puppets (as 
shown in my personal anecdote above), and through my own professional observations of puppeteers caring for their puppets. If, therefore, neuroscience is correct in that by observing and moving in ways which mirror others' physical and mental processes, people's brains are stimulated to feel empathy, it therefore seems reasonable to consider that puppetry practice is an attitude of empathy.

\section{Puppetry as ritual practice}

I will begin the analysis of puppetry, empathy and healing through an examination of how traditional puppetry has historically been connected to healing practices. The social functions of puppetry include ritual practices with the purpose of healing: interceding with gods; journeying with or on behalf of the affected person or community; carrying out performance in order to activate healing processes within participants, as a few examples.

Animated figures, masks and related objects exist and have existed in most human cultures around the world (Blumenthal 2005). The first examples of puppetry we find come from references to animated figures as funerary rites (Jurkowski 2013: 167; Jurkowski and Pawlik 2009: 589). In ancient China puppets accompanied the burial procession; the puppets provide protection for the dead person travelling into another world. This practice can be seen in parts of Africa today. In the Ivory Coast, Cameroon, Nigeria and Gabon, it is believed that puppets assist the dead person to bid farewell to this life (Jurkowski 2013:169-173). Puppets have also been used in childbirth, marriage and adolescent transitional rituals (Jurkowski and Pawlik 2009: 589-94). In Cameroon and Gabon, young men undergoing initiation rituals are blessed by puppets performing their ancestors (Jurkowski 2013: 169). Aya Marweneck locates the potential of puppetry to bind community clearly within its role as a social and ritual practice, drawing attention to the roots of indigenous Southern African puppetry in fertility rituals and healing ceremonies (Marweneck 2016b: 144-147). Her research indicates its power to enact social empathy through community ritual.

In Indonesia, shadow puppet shows are performed during pregnancy and childbirth (to bless the conception and birth); during marriage rituals, and to ward off illness (Jurkowski and Pawlik 2009: 593). In modern-day Taiwan, string puppets are performed in the street after a road accident to collect the dispersed spirits of the person harmed (Cheng 2019). These are a few examples of practices related to healing and wellbeing where puppets play a central part. Puppets are therefore important within transitional processes. The puppet lives in a place in between; perceived as neither here nor not here, neither us nor not-us. The puppet can therefore be a means to assist with journeys and difficult encounters between one place 
and another; one state or another. Illness, pain, trauma, difficulty are all life experiences which force us to meet and go through another difficult, awkward place. In pain, illness and trauma, we are also in between: between the place of no-pain, health and the place where we are better; or where we understand and accept our illness; or the place where we have already become another self through the transitional space of illness. The puppet is a mediator between these states of being; it enables the transition between worlds.

\section{Puppets as accompaniment and witness}

Puppets are also created early on in childhood play as young children learn to bring characters to life; endow their toys, dolls and objects with personality, agency and attributes. Puppets are seen by many children as friends and companions (Majaron 2012). Puppetry is also an art form that has been much practiced by those detained in concentration camps, both for themselves and as entertainment for other prisoners: examples of puppets made in concentration camps during the Second World War can be seen in the object collections at the Historical Museum in Berlin. This is part of a process of mark-making for those perhaps most invisible, literally and symbolically, in social life. By creating a puppet, the prisoners are also creating a material manifestation of themselves: making their existence concrete (Smith 2016).

\section{Social empathy}

Aja Marneweck (2016a) discusses puppetry as radical empathy in situations of trauma, in her work with post-conflict communities in South Africa and Northern Ireland:

It is the inter-relational potential of a creative practice such as puppetry, that facilitates movement between ritual and re-membrance, sentience and construct, spoken and unspoken, self and other, the threshold and the centre....through an 'embodied transference' in the mundus imaginalis of puppetry, the intermediate dimensions of its sentient construction offer keys to a potentially radical empathy that may transmute the reception and experience of trauma.

This research is predicated on the idea that puppets, as ritual and transitional objects, enable the rebuilding of deep community connections via processes which enable people to have compassion towards different social groups. Since the puppet, a collective icon of community 
experience, acts as witness to community trauma, its use is therefore translated into a deep shared empathetic connection between communities, not just individuals.

\section{Key aspects of puppetry performance}

Puppetry is, by its nature, the act of giving or enabling life, anima or energy to another body or material. The puppet is enabled or assisted to perform through the actions of a puppeteer, who gives her or his voice, movement, presence and energy towards the facilitation of the puppet. The focus is therefore necessarily outside the puppeteer's own body and is aimed at showing a series of actions, emotions and reactions which are not necessarily the puppeteer's own. In Astles (2009a), referencing Eugenio Barba (2007), I propose that within puppetry training, the puppeteer directs the energy outside their body through the pre-expressive principles of distraction and continuum. By distraction I refer not to casting one's attention randomly and without focus, but instead 'a concentrated and profound act of attention derived from a sense of giving to something else' (Astles 2009a: 57); this takes place whilst the puppeteer maintains the principle of continuum, which is defined as '.... p process whereby...all movement between puppets, puppeteers and other elements on stage are intrinsically linked, in constant motion and relationality’ (Astles 2009a: 58). This idea, therefore, of giving intense focus, direction and attention to something else is central to puppetry performance and is relevant for this exploration of puppetry and empathy since the process is close to that of cognitive and radical empathy, whereby an active and chosen attitude is taken towards another.

Aside from being a practice of directing attention towards something else, one of the principle elements of puppetry is that it is always a relational encounter. When a puppet is animated, we experience it as being in relation to something: other puppets, humans, its environment, etc. Within popular puppetry, improvisation with the audience is frequently key to the narrative: popular puppet characters all over the world engage with their audiences in banter, improvised dialogues, skits and comic songs. When used in therapy or in hospital contexts, the puppet develops a relationship with the person receiving its attentions (Linn 2019). The nature of that relationship enables the therapeutic encounter. Persephone Sextou (2016) notes that the puppet can offer the child in hospital: 'an opportunity to be actively and interactively responsive to a theatrical event in the midst of the ... lonely ... moments of hospital life' (Sextou 2016: 94-95). The ability to relate, and communicate through relating, is key to empathetic understanding; since puppetry only exists through relationship, there is a further synergy here. 
The form of puppetry which has most enabled this discussion about empathy is the form known as table-top or multi-operated puppetry. This form of puppetry was influenced by Bunraku: traditional Japanese puppet theatre; and is characterised by performances with hand-held puppets operated on 'table-tops' by three people who are arranged around the puppet in close contact.

The key thing to note here is that the puppeteers animate the puppet in collaboration. They do this through close teamwork: listening, following, activating and understanding the anatomy of the puppet. They follow the puppet's movements and do not draw attention to themselves; they work as an ensemble. They learn to develop the skills to do this through breath work, contact movement training and handling the puppet itself. This close attention to breathing and moving as an ensemble, while giving collective attention to the moving object outside their bodies, is fascinating when considering the power it may have to develop connections between puppeteers, and, for the purposes of this study, for developing empathy. By breathing and moving 'into' the puppet, and, indeed, 'feeling into' each other to understand each other's movements, puppeteers are mimicking what is done when people consciously or unconsciously imitate each other's movements and attitudes in order to be more empathetic. My own observations of trainee and professional puppeteers working closely together to animate table-top puppets suggest that, through this training and practice, puppeteers generally develop a close and caring relationship which leads to concern, support and acceptance of each other. Following a period of intense collective training or rehearsal, puppeteers may commonly sit or stand closer together; share resources willingly and without competition; offer practical assistance.

Figure 2. Do ghosts get bored? Puppeteers collaborating on puppetry animation. 29.08.18. Artwork by Cariad Astles. Courtesy of Cariad Astles.

Various scholars have addressed the way in which the puppeteer works alongside, with, and into the puppet and have tried to analyse the phenomenon of embodiment with an object, and the transference of energy into that object. Paul Piris (2014) discusses the concept of 'manipul-acting' in relation to the co-presence of the puppeteer and the puppet on stage. He seeks to define and conceptualise the situation whereby two figures, one human, and one not human, exist and share the same source of energy on stage and yet enter into dialogue and communication with each other. Similarly, Alissa Mello (2016) calls the phenomenological experience of embodiment via a puppet transembodiment: experiencing across bodies. 
Contemporary puppetry no longer considers animating a puppet as an act of control, as may have been the case prior to the last twenty years, in but instead as an act of enabling. Within puppetry studies, trainee puppeteers are encouraged to listen to the material (see Millar 2018; Baker 2009); explore what the puppet wants to do; find the natural movement of the material or puppet that they are working with. Puppeteers therefore work with the idea of deep listening, waiting, responding and engaging with something else. These processes are key to cognitive empathy. All of these explorations into puppetry performance seem to me to be close to the idea of Einfühlung: feeling 'into' something.

\section{Neuroscience, empathy and puppetry explorations}

Over the last decade, interest has grown in the relationship between neuroscience and puppetry and a number of projects have emerged which I will briefly discuss here as background to my own work. Viewing a puppet is largely about perception; through codes of movement, we perceive that it is alive, even if it is not. We perceive that it picks up a cup, even if it does not (and, say, the puppeteer picks it up for it). We understand from research in neuroscience that affective empathy is triggered as much by perception of a movement, gesture, facial expression etc, as it is by it actually being done (Decety and Ickes 2009). Puppetry is an art of suggestion: suggestion of movement, feeling, action, personality. This means that empathy within the audience will be triggered even if that which is presented is only a suggestion, as it is with the puppet. This differs from live acting in that, whereas an actor may actually carry out certain actions, such as eating, speaking, walking, etc., the puppet carries out the illusion of these things. The suspension of belief that takes place in the audience's mind through agreeing to perceive these actions in the puppet may lead to more empathy being triggered, since they have already engaged in cognitive empathy: they have taken the decision to accept and to try and understand the being which pretends to be alive before them.

The puppeteer Stephen Mottram, in discussion with Paul Downing, professor of cognitive neuroscience at the University of Bangor, participated in a discussion about this as part of a series of events set up by the Wellcome Collection in collaboration with the Royal Central School of Speech and Drama in 2012. Mottram noted that puppets enact performance vocabularies which permit the audience to decode movement patterns and emotions, leading to identification with the object or puppet. These movement patterns undertaken by puppets are commonly taught in puppetry training programmes and focus on areas such as balance, counterbalance, twists, lifts, jumps, etc; all designed to examine and explore the anatomy and 
mechanical movement of the puppet in order to be able to better represent the illusion of life on stage. The key thing here, however, is that it is the intention of the puppet which asks the audience to complete the imaginary sentence. Puppetry is an invitation for audiences to make sense of otherwise random movements of material and objects.

Mottram's show The Parachute (2017), takes the idea of perception of movement further; there are no concrete puppets in this show. Mottram instead uses lit-up ping pong balls configured in various choreographies around the stage to explore a poignant story about a man who is reaching the end of his life. The high level of belief, identification, compassion and empathy for the perception of narrative performed by the ping pong balls is remarkable considering that there are in fact no figures at all on stage. This relates to the idea that empathy is achieved through perception of movement and emotion.

A puppetry project, Animating the Brain, was developed between the puppet company Theatre Rites and the Department of Neurobiology at Kings College London in 2015. This project explored how similar the processes are for neuroscientists investigating the brain and puppeteers bringing the brain of a puppet to life. In 2017 the team took the show arising from the project, The Incredible Tale of Robot Boy, into Great Ormond Street Hospital for children, to assist with patients' perception of their own brains and their treatment. Where children received particular intervention in the form of brain surgery to assist them with their own functioning, they could relate it to the way in which Robot Boy was enabled to function by the puppeteers (Theatre Rites 2019).

Puppeteer Rachel Warr of Dotted Line Theatre, and Roger Kneebone, Professor of Surgical Education and Engagement Science at Imperial College, London, found that there was great resonance between the worlds of the practising medical surgeon and the puppeteer in a project discussed later in this issue by Warr herself. Both Warr and Kneebone were struck by the close and collaborative relationship between teams of puppeteers and teams of surgeons which depended not upon instructions to each other, but on a physical collaborative relationship based on sensing each other's needs, movements, and practices; indeed, being empathetic towards each other. Kneebone (2019) notes that:

Underpinning (the surgical team) remains the need for team members to work together, communicating effectively without the usual cues of social interaction such as eye contact and facial expression. They must be able to 'read' one another's bodies as they stand huddled together around a vulnerable patient, coordinating their actions in a seamless surgical choreography. 
Puppeteer Oli Smart held a dialogue via his puppets with systemic psychotherapist Mark Huhnen, in which the life of the puppets is discussed: 'Interviews with Puppets - and Oliver Smart - with Mark Huhnen' (Smart and Huhnen 2018). In this video, the puppet draws attention to the need for witness - an aspect of the puppet that I have highlighted in this article: 'The reason why I feel as though I am alive is because I am in front of you', says a puppet (who thinks he is partly a hat). He continues, 'My feeling of being alive has got something to do with being in front of you...rather than independently...I have a life which is completely dependent on those people who are watching me...' He says to the human in conversation with him:

I think that you think that you are not an object because you are animating yourself from inside and you can't see the object that is being animated, whereas everything you see on the outside you objectify in some way....it is just what you perceive....' (Smart and Huhnen 2018)

This affecting conversation draws attention to the perceptual nature of puppetry.

Puppets may also enact real-life medical situations, generating empathy about those situations. The medical school at the University of Warwick and the Little Angel Theatre collaborated on a production of Passing On in 2011, a piece about end of life care. In this production, directed by Claudette Bryanston, a life-sized puppet represents a woman reflecting upon the quality of care given as she faces her last days. Due to the depersonalisation of the puppet, she is able to raise taboo and difficult experiences whilst generating deep empathy for those experiences (Bryanston 2011).

The neurologist Rodolfo Llinás interviewed New York-based puppeteer Roman Paska in a series of talks as part of the Brainwaves festival held at the Rubin Museum of Art in New York in 2011 (Llinás and Paska 2011). During the talk, Llinás discussed a particular project that he had been working on which involved testing the brain of the puppeteer during the process of animating puppets, and confirmed that those areas of the brain believed to be connected to empathy were detected to be highly active during this experiment.

Drawing on Maurice Merleau-Ponty, we can consider the puppet as a form of relational embodiment. Merleau-Ponty (1968) notes that in relational embodiment, there is a 'reciprocal insertion and entwining' of others in oneself (138). Just as the puppet (as expressed by Smart above) exists in relation to both the puppeteer/s and to their audience, 
humans also experience their sense of embodiment and consciousness in relationship; puppets have the capacity, it seems, to invoke this sense of empathetic relationship with others.

Having viewed and analysed the performances and projects above, and the effects of relational embodiment in my own practice, I was struck, throughout all my research into and definitions of empathy, by the continued use of the word 'into'. This sense of going into and experiencing together, collectively, collaboratively, is at the heart of puppetry practice. The puppeteer performs into the puppet in order to animate it; the audience is invited to go into the world of the puppet to engage and empathise. Why, then, is this so important in healthcare?

\section{Puppetry, empathy and healthcare}

Within contemporary healthcare practices, puppets are quite frequently used by play therapists and appear in hospital wards; in programmes for healthcare education; as intermediaries in therapeutic contexts; as a means to engage imagination and creativity for those with dementia; increasingly in training for doctors and other medical staff. These interventions depend on local puppeteers, practitioner-scholars undertaking research in the health humanities and related fields, and arts in health programmes, which vary enormously across countries and regions.

I posit that the capacity of the puppet to both stimulate empathy in the brain and body of the puppeteer, through going 'into' the body, mind and, I dare to say, the spirit of an-other, and to generate empathy in the consciousness of the audience, is related to the ritual position of the puppet as mediator as discussed above, and could therefore offer a concrete, practical and beneficial medium for communicating with colleagues working in healthcare, patients and other involved parties. Its increased and more widespread use as a playful method of training and communication would develop the work of caregivers and medical professionals considerably.

To return to its ritual aspects, where the puppet performs the role of a transitional object, as in the case of funeral rituals, it offers some protection to the ego when entering into a dangerous or unknown place or transition. Here the puppet becomes an empathetic presence itself. Its capacity to mediate has been used, for instance, in cases of child abuse where the puppet has been used to represent the abuser, or members of the child's immediate surroundings, where the actual names are too dangerous to be mentioned (Gil and Smelser 2018); it has been used in community development when parties in conflict are not able to 
speak directly to each other (Astles 2009b: 646); and in healing rituals as mentioned earlier. Puppetry in healthcare is therefore important as mediation. A project that I ran with students at Torbay Hospital in 2011, included puppetry making and training with therapists on the stroke ward. The patients were largely unable to speak or to express their wishes and so the therapists used puppets to express different emotions. The patients were mostly able to indicate which of the puppets they felt like. The 'emotion puppets' here acted as mediators between patients and therapists to enable empathetic communication. Where the puppet is used as mediator, it is a useful tool and more widespread use could contribute significantly to the emotional safety of people working in situations of fragile health.

The second aspect that is specific to puppetry when discussing empathy and healthcare, is the puppet's capacity to accompany. The puppeteer, audience or owner/creator of the puppet use it as a vessel into which to pour their fantasies, fears and hopes. This capacity to safely carry deep and powerful emotion means that it can act as a powerful companion. The work done by, for instance, Susan Linn (who works with children in hospitals and healthcare settings to explore their emotions), Persephone Sextou (who brings hospital and bedside performances to children in hospitals) and myself (working in hospital wards to explore healthcare conditions and to present bedside performances) in hospital settings uses puppets as accompaniment. This work, primarily done with children, uses puppets to accompany children into operations, to distract or entertain them at times of pain or trauma, or as companions on the hospital ward and works towards the idea of empathetic companionship (Sextou 2016; Linn 2019).

Fear and distress are common emotions experienced by people in hospital. Amanda Cunha, Danielle Pio and Thais Raccioni (2017) suggest that fear and distress can be reduced by 'therapeutic accompaniment' and that accompaniment therefore contributes to the healing process and holistic improvement of the patient's condition. The puppet is important, therefore, as a perceived empathetic and therapeutic companion for children and others experiencing fear and distress in medical situations. This approach is similar in puppetry work with people with dementia where the puppet is perceived by the person with dementia as a non-human but living and sympathetic presence alongside themselves, who listens without judgment. The puppeteer Karrie Marshall gave a talk at Hands On!, a conference of applied puppetry at the Little Angel Theatre, in which she discussed a powerful narrative of an experience she had working in a care home with a man who had not spoken for months; she simply accompanied him with a puppet, which sat alongside him without speaking. One day, the man unexpectedly and suddenly broke into song and turned in recognition to greet 
the puppet (Marshall 2011). This moving experience is testimony to the idea that the puppet is a non-judgmental and accepting companion.

Thirdly, the puppet acts as witness. The act of testifying or witnessing an event is understood to be a key ways through which people confirm behaviour, actions and facts about human lives and verify their existence. Increasingly, health, or good health, is understood to be a subjective experience of self within the world rather than as a set of physical symptoms or lack of these. Testimony acknowledges and confirms existence. Making or using a puppet has a powerful function for people who, through it, are able to mark their identity, existence and presence. Corina Duyn (2017), who suffers with M.E., gave a talk at Broken Puppet 1, University of Cork, about how working with puppets had enabled her to mark the story of her experience of living with illness. Moreover, the puppet used to tell real stories of illness, disability or other related conditions, such as the end of life example given earlier, enables people to engage with these conditions through the empathetic response created when viewing puppets.

In 2011, 2012 and 2013 I led a puppetry project in care homes, at memory cafés and a day healthcare centre for people with different stages of dementia, with students from the Royal Central School of Speech and Drama. The intention was to use puppetry to engage in meaningful dialogue and interaction with residents of the care homes and users of the day centre; to empathise with them and assist them in developing a sense of purpose. Interactive stories were created based on 'relationship theatre', a form of applied theatre. The primary stories within these performances introduced the residents and visitors to a set of characters and some of their life dilemmas to do with love, family, jobs and even pets. The audiences were invited to empathise with the puppets in order to solve their problems, and to share their own stories and life dilemmas to be performed by the puppets. Through understanding and identifying with the puppets, the participants were able to explore their problems and situations comically and without it becoming threatening.

We can see from the above that it is not only the puppeteer and audience who are enabled to be empathetic through puppetry; the puppet can also be sensed or perceived as an empathetic presence for the vulnerable. This occurs through these three qualities of the puppet: mediation, accompaniment and testimony. The accounts above suggest that people can feel that they are understood and accepted by the puppet. This makes it particularly valuable when working in healthcare settings.

\section{Empathy, puppetry and healing}


Triggering empathy is not only important for audiences and puppeteers, but also for those working with people in healthcare. As I observe earlier, training in puppetry seems to be directly related to the activation of the areas within the brain responsible for generosity and empathy. I therefore consider puppetry performance to be training in profound care or compassionate empathy, when linked to actions of care driven by deeper understanding of others.

When teaching puppetry animation to medical students at the University of Exeter, I noted that they expressed surprising levels of care towards the puppet body that they were animating, and also higher levels of emotional response towards their fellow puppeteers when engaged in these exercises. The medical students commented that they felt 'deep empathy' for the puppets and wanted to 'care for them'. They also commented that the work with puppets encouraged them to think more deeply about how they would treat the patients that they worked with. At the University of Ulster, Dr Matt Jennings (2017) works with Banyan Puppet Company on a project where medical staff learn about handling of and carrying, and caring for, other bodies through the use of life-sized puppets. In this project, trainee nurses, emergency paramedics and other medical caregivers are trained in the principles of puppetry movement and animation through the use of medical mannequins.

These, and other projects, are important because empathy as healing is gaining in importance and recognition. Paul Dieppe, Professor of Health and Wellbeing at Exeter Medical School, believes that empathy is more important than science for healing:

Healers are helping us to activate that mechanism which, for some reason, we have forgotten in our culture. Some call the process unconditional love. If that's too difficult, my shorthand for it is 'total attention with good intention'. It's about having a totally unconditional desire for the other person to get better (Evans 2015).

The fields of medicine and surgery are still dominated by 'empirical' medical data-led methods of evaluating diagnosis, treatment and care, and more humanistic, holistic and empathetic modes of care are still in the minority. Helen Riess (2017) notes, worryingly, that empathy is known to diminish during medical training, yet suggests that the broader field of healing is supported by the practice of radical empathy.

It is clear from the above narratives that puppetry has a place in affective, cognitive and social empathy predicated on a relational entwinement of puppeteer, audience or participant, and puppet. Marina Tsaplina and Astles (2020) note that 'puppetry's intrinsic 
construction of the 'illusion of life' allows for training the practice of perception...the puppet-object ... is able to hold and expand the relationship to it (297). The expansion of a developing relationship is key to the idea of empathy as a flowing relational encounter. By expanded relationship I mean that the relationship is open-ended; it can develop; the puppet is able to be accepted for what it is, without stereotyping or intervention. Similarly, the puppet accepts the world for what it is; it engages with things as it finds them. Puppetry draws attention to what is, and enables journeying into difficult areas. Puppetry opens up dialogue; by understanding and feeling into, puppeteers and audiences are encouraged to take action to support and assist other bodies. It therefore functions as social empathy, and, lastly, by performers actively performing into the puppet, and training to do so, they are performing a form of radical empathy.

\section{Conclusion}

This article traces clear synergies between puppetry practice and research into empathy and examines ways in which puppetry and medicine do and can work together to enable radical empathetic responses to people in need of care. It further explores the connections created through the activation of empathy when performing puppetry. My proposal, arising from the analyses of these synergies, and from my own practice, is that, firstly, puppetry performance practice is highly likely to increase empathy within both performers and audiences, whether this is cognitive, affective or prosocial empathy. Working with puppets and watching puppets increases the potential for empathy. Working with puppets in training of medical professionals can also increase the capacity for heightened care through empathy for an-other body. Finally, the puppet itself can be perceived as empathetic presence alongside the vulnerable. This relates to the puppet's ontological and ritual use as mediator, companion and witness through traumatic experience or change. The presence of the puppet alongside someone experiencing distress or transition, as in healthcare settings, as a non-judgmental and empathetic presence, can reduce distress. As noted above by Keysers and Gazzola of the Social Brain Lab, perception of a condition or state can trigger empathy in the same way as the phenomenological experience of the condition. These analyses and findings have resonance for the value of puppetry as a perceived body or presence within multiple modes of healthcare training and practice, as a way of developing sensibility towards proempathetic response.

\section{References}


Armstrong, Kim (2017), 'I feel your pain: The neuroscience of empathy', The Association of Psychological Science, https://www.psychologicalscience.org/observer/i-feel-yourpain-the-neuroscience-of-empathy. Accessed 27 March 2020.

Astles, Cariad (2009a), 'Wood and waterfall: Puppetry training and its anthropology', Performance Research: On Training, 14: 2, pp. 54-59.

Astles, Cariad (2009b), 'Small world theatre', in H. Jurkowski and H. Foulc (eds.), Encyclopédie Mondiale des arts de la Marionnette, Montpellier: UNIMA/Entretemps, p. 646.

Baker, Rene (2008), 'Listening to the material', Theatre Materials, Royal Central School of Speech and Drama, London, 18 April 2008.

Barba, Eugenio and Savarese, Nicola (2007), 'Pre-expressivity', in J. Keefe and S, Murray (eds), Physical Theatres:A Critical Reader, London: Routledge.

Bloom, Paul (2016), Against Empathy: The Case for Rational Compassion, New York: Harper Collins.

Blumenthal, Eileen (2005), Puppetry and Puppets: An Illustrated World Survey, London: Thames and Hudson.

Bryanston, Claudette (dir.) (2011), Passing On, M. Kenny, University of Warwick, Santé Theatre Warwick, 29 - 31 October 2011.

Caswell, Michelle and Marika Cifor (2016), 'Human rights to feminist empathy: Radical empathy in the archives', Archivaria, No. 81, pp. 23-43.

Decety, Jean, and Ickes, William (eds.) (2009), Social Neuroscience. The Social Neuroscience of Empathy, Cambridge, Massachusetts: MIT Press.

Duyn, Corina (2017), 'Life outside the box: Puppetry, M.E. and disability', Broken Puppet Symposium, University of Cork, Cork, 2 August 2017.

Eisenberg, Nancy and Strayer, Janet (1987), Empathy and its Development, Cambridge: Cambridge University Press.

Evans, Jules (2015), 'Paul Dieppe on spirituality, ritual and the healing process', The History of Emotions blog, 23 January 2015, https://emotionsblog.history.qmul.ac.uk/2015/01/paul-dieppe-on-spirituality-ritualand-the-healing-response/. Accessed 21 November 2019.

Gil, Eliana, and Smelser, Quinn (2018), 'Puppets in family therapy with a case of trauma and sexual abuse', in A. Drewes and C. E. Schaefer (eds.), Puppet Play Therapy: A Practical Guidebook, London: Routledge, pp. 165-173. 
Jennings, Matt (2017), 'Applied puppetry and sympathetic presence in medical simulation and nursing pedagogy', Broken Puppet Symposium, Cork: University of Cork, Cork, 2 August 2017.

Jurkowski, Henryk and Pawlik, Jaček (2009), 'Rites', in H. Jurkowski and H. Foulc (eds.), Encyclopédie Mondiale des arts de la Marionnette, Montpellier: UNIMA/Entretemps, pp. 589-94.

Jurkowski, Henryk (2013), Aspects of Puppet Theatre, Basingstoke: Palgrave Macmillan.

Kneebone, Roger (2019), 'The myth of the lone heroic surgeon', lecture delivered at Museum of London, London, 27 February 2019, https://www.gresham.ac.uk/lectures-andevents/lone-heroic-surgeon. Accessed 10 November 2019.

Koss-Chioino, Joan (2006), 'Spiritual transformation, relation and radical empathy: Core components of the ritual healing process', Transcultural Psychiatry, 43: 4, pp. 65556.

Linn, Susan (2019), 'Puppets in hospital talking about feelings and difficult topics', Sana, Sana: jornadas internacionales del títere, Madrid, 12-14 September 2019.

Llinás, Rodolfo and Paska, Roman (2011), 'A dream on a string', talk delivered at the Rubin Museum of Art, New York, 30 March 2011.

Majaron, Edi (2012), 'Art as a pathway to the Child,' in L. Kroflin (ed), The Power of the Puppet, Zagreb: UNIMA.

Malikiosi-Loizos, Maria (2003), 'A critical look at empathy', Psychology: The Journal of the Hellenic Psychological Society, 10: 2-3, pp. 295-309.

Marneweck, Aja (2016a), 'Puppetry as radical empathy: Transmuting personal and communal trauma through animism-based performance practices', Removing Apartheid: Postdramatic and Postnarrative Modes of Coping with Trauma, University of Ghent, Ghent, 28-30 September 2016.

Marneweck, Aya (2016b), 'Sexual and spiritual r-evolution through animism: The feminine semiotics of puppetry', Journal of Resistance Studies, 2: 2, pp. 134 -166.

Marsh, Abigail (2018), 'The neuroscience of empathy', Current Opinion in Behavioural Sciences, 19, pp. 110-115.

Marshall, Karrie (2011), 'Zenwing Puppets: Puppetry and dementia', Hands On!, Little Angel Theatre, London, 28 January 2011.

Mello, Alissa (2016), 'Trans-embodiment: Embodied practice in puppet and material performance', A Journal of the Performing Arts, 21: 5, pp. 49-58. 
Merleau-Ponty, Maurice (1968), The Visible and the Invisible, Evanston: Northwestern University Press.

Millar, Mervyn (2018), Puppetry: How to Do It, London: Nick Hern Books.

Mottram, Stephen (2011), 'On the mask effect in puppetry manipulation' in Fantoche: Arte de los títeres No. 5, Madrid: UNIMA Federación España, pp. 12-17.

Mottram, Stephen (2012), 'Master of Manipulation', talk given at the Wellcome Collection, London, 12 May 2012, http://www.stephenmottram.com/otherwork.html?LMCL=mhJElU. Accessed 14 December 2019.

Mottram, Stephen (dir.) (2017), The Parachute, Stephen Mottram, Jackson's Lane Theatre, 16-25 January 2017.

Piris, Paul (2014), 'The co-presence and ontological ambiguity of the puppet' in D. Posner, C. Orenstein, and J. Bell (eds), The Routledge Companion to Puppetry and Material Performance, London: Routledge, pp. $30-42$.

Riess, Helen (2017), 'The science of empathy', The Journal of Patient Experience, 4: 2, pp. $74-77$.

Sextou, Persephone (2016), Theatre for Children in Hospital: The Gift of Compassion, Bristol: Intellect.

Smart, Oliver and Huhnen, Mark (2018), 'Interviews with Puppets - and Oliver Smart - with Mark Huhnen', Vimeo, https://vimeo.com/326637300. Accessed 2 March 2020.

Smith, Matt (2016), 'Thinking through the puppet, inside and outside immigration detention', Applied Theatre Research, 4: 2, pp. 147-159.

Theatre Rites (2020), 'Animating the Brain', https://theatrerites.co.uk/show.php?id=18\&title=The_Brain. Accessed 12 December 2019.

Tsaplina, Marina and Astles, Cariad (2020), 'The art of puppetry practice: Embodiment, enchantment, memory, history', in P. Crawford, B. Brown and A. Charice (eds.), Routledge Companion to the Health Humanities, London: Routledge, pp. 296-30.

Tudor, Keith (2011), 'Understanding empathy', Transactional Analysis Journal, 41: 1, pp. $39-57$.

\section{Contributor details}

Cariad Astles is Course Leader for the BA Puppetry at the Royal Central School of Speech and Drama and is also Lecturer in Drama at the University of Exeter, UK. She is President of the Research Commission for the international puppetry association, the Union Internationale 
de la Marionnette. Cariad specialises in training, researching, performing and directing for puppet theatre; in objects and puppets within healthcare and applied settings and in the puppet as marker of political and cultural identity. She frequently runs training workshops in the UK and overseas, most recently in China, Chile, Australia, Germany, France and Spain.

Contact: Royal Central School of Speech and Drama, Eton Avenue, London NW3 3HY, UK.

Email: c.astles@cssd.ac.uk; c.astles@exeter.ac.uk

Orcid: 0000-0001-6327-8980

\footnotetext{
${ }^{1}$ fMRI refers to the technique of functional magnetic resonance imaging, whereby brain activity can be detected through seeing the levels of brain oxygenation and flow in different areas of the brain and neural pathways.

${ }^{2}$ This acronym refers to transcranial magnetic stimulation: a technique used to measure activity and function of brain circuits.
} 